\title{
PEDRO LUIS DE TORREGROSA, PRIMER \\ CONTADOR DEL LIBRO DE CAXA DE FELIPE II. \\ INTRODUCCION DE LA CONTABILIDAD \\ POR PARTIDA DOBLE EN LA REAL \\ HACIENDA DE CASTILLA (1592)*
}

\author{
ESTEBAN HERNANDEZ ESTEVE \\ Banco de España
}

Los reinados de los dos primeros Austrias españoles se encuentran cuajados de intentos y esfuerzos por dotar de más eficacia y control a la gestión financiera de la Corona, superando los inconvenientes de la gran dispersión y desparramamiento del aparato hacendístico, no menos grave, a estos efectos, que la corrupción propia de la época y que la falta de un funcionariado organizado y eficiente.

Aunque algunos de estos intentos alcanzaron resultados más o menos positivos, no puede uno evitar, sin embargo, una leve sensación de punzante patetismo al asomarse a todo este contexto, a este incesante $y$ angustioso ir $y$ venir de los monarcas en pos de unos frutos que sólo cosechaban en medida parca y desproporcionada. Pero su urgencia era grande, y la necesidad de más y más fondos para financiar su política de liderazgo europeo les forzaba a la instrumentación de nuevos arbitrios y a una mejor canalización y administración de los fondos recaudados.

No es, así, de extrañar que buena parte de estos intentos estribara, en mayor o menor grado, en la forma de llevar o rendir las cuentas. El más importante de estos empeños, que he estudiado en otros sitios, es seguramente el supuesto por el proceso de creación del Consejo de Hacienda de Castilla, que se desarrolla durante los años 1523 a 1525 , y a través del cual el joven Carlos $\mathrm{V}$ busca un control mayor y más directo sobre la recaudación y disposición de sus rentas, con la institución de las figuras del escribano y del secretario de finanzas, independizándose de esta manera, en cierta medida, de las poderosas Contadurías Mayores, la de Hacienda y la de Cuentas, que se encuentra ya montadas a su llegada a España '.

* El trabajo que sigue es un breve resumen de la ponencia presentada en las Journées Internationales d'Histoire du Droit, celebradas en Amsterdam del 22 al 25 de mayo de 1984.

' Véanse mis trabajos al respecto: $1983 a, 1983 b$ y $1984 a$. 
Un segundo empeño a destacar, aunque de índole algo distinta, es la obligación que impone a todos los mercaderes y banqueros residentes en España de llevar sus cuentas, precisamente, por medio de la partida doble, de acuerdo con lo dispuesto en las pragmáticas de Cigales, de 4 de diciembre de 1549, y de Madrid, de 11 de marzo de 1552. De esta manera, se esperaba una mayor facilidad para investigar y reconstruir el proceso seguido por las operaciones realizadas por los comerciantes, de forma que se les dificultara efectivamente el incumplimiento de las disposiciones legales prohibiendo la evasión de moneda y de metales preciosos fuera de las fronteras españolas. Con esta medida, España se adelantó grandemente al resto de los países europeos en lo concerniente a la promulgación de una normativa legal sobre los libros de cuentas y el sistema a emplear para llevarlos ${ }^{2}$.

Poco después, se produjo otro intento significativo en ese sentido de intentar dirigir y controlar mejor la marcha de los asuntos de la Real Hacienda: el establecimiento oficial del «libro de la razón», que tuvo lugar por cédula de Torrejoncillo, de 9 de mayo de 1554. En realidad, el libro de la razón parece que lo había empezado a llevar directamente, por propia iniciativa, el contador Francisco de Almaguer hacia 1543, pero hasta el citado año no tuvo lugar la creación del oficio. Este libro debía «tener cargo y cuidado de tomar la razon de ella [la Real Hacienda] de los nuestros reinos de la corona de Castilla, y que esto vaya y se haga por una mano, para que se tenga cuenta particular y general con todos, y que siempre que lo quisieremos saber por escrito o de palabra, se nos pueda dar" ${ }^{3}$.

En el mismo sentido apuntado, cabe destacar la implantación en 1556 de un sistema de factores del rey, con el nombramiento de Fernán López del Campo como «Factor General de su Majestad en los reinos y señoríos de España», según cédula despachada en Gante, el 22 de septiembre del citado año. La figura y denominación de factor procedían del mundo de los negocios, y servían para designar al gerente o encargado de la gestión del establecimiento comercial en lugar distinto, por lo regular, al de la sede principal. El nombre de factor general podría traducirse hoy, pues, por el de director general o consejero delegado de una empresa, y, efectivamente, las facultades dadas por Felipe II a su representante estaban en consonancia con esta idea ${ }^{4}$.

Otro intento notable es el supuesto por la reorganización del oficio de tesorero general, dictada, aunque parece que sin mucho efecto, en 1575, y vuel-

'He estudiado con algún detalle esta cuestión en mi trabajo 1981.

${ }^{3}$ Archivo General de Simancas, Contaduría Mayor de Cuentas, 3.' época, leg. 223, do cumento núm. 247.

4 E. Hernández Esteve, 1984 b. 
ta a acordar en 7 de marzo de 1584. Se acabó de perfilar esta reorganización por cédula del 8 de mayo del mismo año, quedando establecido un sistema merced al cual el rey nombraba dos tesoreros generales que debían ejercer su oficio, de forma alternativa, por períodos de dos años, empleando los dos que no ejerciesen en preparar y rendir las cuentas de los dos años anteriores en que estuvieron ejerciendo ${ }^{5}$.

El último intento conocido en el sentido que nos interesa es el que se presenta en este trabajo, relativo al establecimiento en 1592 de la contabilidad por partida doble para llevar las cuentas centrales de la Real Hacienda castellana. Tal vez sea, además, la reforma que mejor muestra la admiración y acercamiento de los dos primeros Austrias españoles respecto de los métodos empleados por los banqueros y grandes hombres de negocios privados, presentes en toda la cadena de empeños que hemos ido señalando, en una insólita muestra de sensibilidad, por parte de la autoridad política, para percibir dónde se encontraban los que realmente sabían de sus materias.

La presente investigación estudia este interesante intento, por el que España se adelanta también notablemente al resto de los países europeos de la época, según lo que hasta hoy sabemos. De hecho, el único país que sigue a España bastante de cerca en este campo es Suecia, que en 1623 implantó, asimismo, la partida doble para llevar las cuentas generales de su Hacienda Pública.

En lo que se refiere a España, el intento de 1592 no supone el primer proyecto de implantar la contabilidad por partida doble o sistema del «libro de caxa con su manual», como se decía a la sazón, para llevar cuentas de administraciones públicas parciales o aisladas, pero sí para llevar con carácter centralizado las cuentas generales de toda la Real Hacienda de Castilla. Por otra parte, no era la primera vez que este planteamiento se intentaba, pues se ensayó ya, sin resultado, por cédula de Badajoz de 9 de julio de 1580, después de varios años de hablarse de la conveniencia de echar mano de este sistema contable.

Hay que advertir, además, que, en rigor, la presente investigación no constituye una auténtica primicia, aunque sí un anticipo y una promesa. No constituye una auténtica primicia por cuanto en varios trabajos anteriores he venido anunciando ya esta buena nueva; la anunciaba, sin embargo, sólo a título de noticia, sin entrar propiamente en el tema. Por otro lado, tengo sumo gusto en reconocer que la luz roja de alarma, la indicación de que algo relevante sucedía en 1592 con las cuentas del Tesoro Público en Castilla, se la debo a un artículo del ilustre historiador del derecho español Rogelio Pérez-Bustamante: "Un intento de reforma contable en la Hacienda española durante el reina-

s Margarita Cuartas ha dado breve noticia de esta reforma. Véase su trabajo 1981. 
do de Felipe II: el Libro de Caja» ${ }^{6}$. En este artículo, aun sin llegar a esta. blecer que la reforma emprendida suponía la implantación de la contabilidad por partida doble, Pérez-Bustamante describe perfectamente las principales vicisitudes que siguió esta implantación, según las relata un documento que descubre y presenta: Relacion de lo que passo, sobre la introducion del libro de caxa de la Real Hazienda?

Alertado de lo que sucedía por este artículo, dediqué mis esfuerzos a la investigación del tema, que se me antojaba prometedor. Lo que aquí se presenta es un simple anticipo, un mero planteamiento y una primera aproximación a la problemática, en donde sólo he utilizado una pequeña parte del material recogido al respecto, muy abundante, sin contar el que todavía descansa en los archivos, completamente desconocido, ni el que, posiblemente, haya quedado destruido, por desgracia, con el correr de los años. Quedo emplazado, pues, a seguir mis investigaciones y a presentarlas en breve con mayor extensión, detalle y profundidad.

Pedro Luis de Torregrosa no era una figura totalmente desconocida antes de comenzar mi investigación. En realidad, pertenece a ese grupo de doscientas o trescientas personas cuyo nombre se encuentra, de vez en cuando, citado de pasada por los historiadores del siglo XVI, que no se detienen, sin embargo, a averiguar bien quiénes eran ni lo que hacian. Les basta con mencionar su existencia, en relación con algún negocio ocasional, surgido al filo de las indagaciones.

Los escasos datos concretos, conocidos y citados por esos historiadores, constituyeron el punto de partida de las pesquisas realizadas en el contexto de esta investigación, que comenzaron en seguida a engrosar el acervo de datos disponibles.

Como consecuencia de todo ello, sabemos que Pedro Luis de Torregrosa nació en Valencia hacia el año $1522^{8}$, muriendo en Madrid el viernes 12 de octubre de $1607^{9}$. Dejó tres hijas, María, Beatriz y Ana, y un hijo, Gerónimo de Torregrosa. Una de las hijas era soltera, mientras las dos restantes

R. Pérez Bustamante, 1979.

' Esta Relación se halla en la Biblioteca de la Real Academia de la Historia, Colección Salazar, tomo T.53.

- Archivo Histórico Nacional, sección de Consejos, leg. 4417, expediente 197; Biblioteca Nacional, Mss. 1750, fol. 364 r.:

${ }^{9}$ Archivo General de Simancas, Quitaciones de Corte, leg. 38. 
estaban casadas ${ }^{10}$. De ellas, Beatriz era la esposa de Pedro de la Torre Espinosa, vecino de Sevilla y pariente, por parte de madre, de la célebre familia de los Espinosa, con núcleo en Medina de Rioseco, de la que también era miembro Juan Fernández de Espinosa, tesorero general del rey y poderoso comerciante ". Pertenecía, asimismo, a esta familia Pedro de Medina, padrino de Bartolomé Salvador de Solórzano, autor del primer libro español de contabilidad por partida doble ${ }^{12}$. El padre del esposo de Beatriz era Pedro de la Torre, tesorero de la ceca de Sevilla y conocido mercader.

Parece que Pedro Luis de Torregrosa procedía de una familia de comerciantes, de la que también eran miembros Jaime y Vicente de Torregrosa ${ }^{13}$, y estaba afincado en Sevilla, aunque bien pronto le encontramos entregado, primero esporádicamente y luego de forma definitiva, al servicio del rey. Llegó a disfrutar, según todos los indicios, de una desahogada posición económica, aunque sus hijos denuncian que murió en la pobreza, teniendo que aceptar un donativo de la Real Hacienda, de 1.500 reales, para poder sufragar los gastos del sepelio, según manifiestan al rey en una Relacion de los servicios del Contador Pedro Luys de Torregrosa ${ }^{14}$.

Durante el tiempo de su estancia en Sevilla, antes de dedicarse definitivamente al servicio de la Corona, fue nombrado veinticuatro o consejero municipal, parece que entre 1565 y 1567 . Residía en unas «casas principales» en la colación de Santa María, en la plazuela del «Atambor», situada al comienzo de la actual calle de Rodrigo Caro, en la confluencia con Mateos Gago ${ }^{15}$. Era propietario, además, de la villa de Torregrosa, sujeta a la jurisdicción de Sevilla, que comprendía varias heredades, con caseríos, olivares y viñas ${ }^{16}$. Sabemos también que compró durante su vida varios juros y censos de importes considerables, que combinaba normalmente con operaciones de fianza y aval de asientos o contratos, concertados ora con Lucián Centurión, ora con Nicolás de Grimaldo, con Agustín Gentil o con Agustín Spínola, todos ellos conocidos mercaderes y hombres de negocios italianos de la

"Relacion de los servicios del Contador Pedro Luys de Torregrosa, nuestro padre, que aya gloria, bizo a su Magestad en utilidad de su Real patrimonio, Biblioteca de la Real Academia de la Historia, Colección Salazar, tomo N-49.

" G. Lohmann Villena, 1968, p. 117. Véase también, en relación con este parentesco, Archivo General de Simancas, Consejo y Juntas de Hacienda, leg. 2017.

${ }^{12}$ E. Hernández Esteve, 1983 c, p. 146.

13 G. Lohmann Villena, 1968 , p. 117, en relación con su parentesco con Jaime de Torregrosa. Vicente de Torregrosa aparece como fiador en un «Proceso executivo*, Archivo General de Simancas, Expedientes de Hacienda, leg. 753, núm. 45, Sevilla, 13 de agosto de 1578 .

14 Biblioteca de la Real Academia de la Historia, Colección Salazar, tomo N-49.

15 *Execuçion en vienes Raiçes", Sevilla, 13 de agosto de 1578, Archivo General de Simancas, Expedientes de Hacienda, leg. 753, núm. 45.

${ }_{16}$ Archivo General de Sinuancas, Mercedes y Privilegios, leg. 228, expediente 74. 
época ${ }^{17}$. Por lo demás, 'parece que Torregrosa era muy conocido en medios italianos, tanto por su riqueza como por su sabiduría y hombría de bien. Así, un contemporáneo suyo indica que hallándose una vez en Génova, hacia el año 1560 , en plena plaza de la Señoría, hablando de comerciantes españoles, le comentaron los allí presentes en relación con Pedro Luis de Torregrosa que con alcanzar éste "tanta riqueza, mayor fama le hacían allá en Italia de su rectitud, buena consciencia, y generosidad, que de la haciendas ${ }^{18}$.

En varios asientos que concertó con la Corona para asumir, por propia cuenta, la recaudación de rentas reales, se manejaron también grandes sumas de dinero. Conocemos bastante bien estas operaciones, gracias a la documentación reunida. En cambio, no sabemos casi nada de los negocios propiamente privados emprendidos por Torregrosa, aunque puede colegirse que debieron de ser de cierta importancia, a juzgar por la posición y prestigio alcanzados, por la categoría de sus asociados e interlocutores, así como por el profundo conocimiento de las relaciones mercantiles que demuestra en algunos de sus escritos al rey. Sólo sabemos que hacia 1564 se dedicaba activamente al comercio de perlas, al igual que su cuñado Pedro de Alcocer. Según una averiguación de la época, parece que Pedro Luis de Torregrosa era el más adinerado de todos los mercaderes que se dedicaban al trato perlifero ${ }^{19}$. También conocemos que durante algún tiempo tuvo abierta una casa de banca en Sevilla, igual que Pedro de Morga, Gregorio de Espinosa y Herveres; los cuatro tuvieron que cerrar, empero, por orden del Ayuntamiento, por no haber efectuado el depósito de las oportunas fianzas. La clausura del negocio se hizo en los cuatro casos con toda normalidad, saldando religiosamente sus cuentas ${ }^{20}$.

Sobre su carrera al servicio del monarca, que cubre la mayor parte de su vida, conocemos mayores detalles. Su trayectoria profesional en este aspecto puede decirse que fue amplia y distinguida, llegando a gozar de la confianza y aprecio de Felipe II y del respeto de los círculos financieros de la Corte. Francisco de Molina, el tercer y último contador del libro de Caja de la Real Hacienda, escribía de él, diez o doce años después de su muerte, que había sido uno de los grandes ministros con que había contado Felipe II,

${ }^{17}$ Archivo General de Simancas, Mercedes y Privilegios, leg. 193, expediente 35. Véase también la documentación citada en la nota anterior.

1s Pedro Madariaga, 1777, pp. 73 y s. La primera edición de este libro fue publicada en 1565. Debo esta noticia sobre Torregrosa a la amable indicación de mi buen amigo José María González Ferrando.

"Archivo General de Simancas, Diversos de Castilla, leg. 46, núm. 106: *Averiguación en el negocio del trato de las perlas en Sevillaw. Debo la pista de esta averiguación a Eufemio Lorenzo Sanz, que la ofrece en su excelente obra: 1980, vol. 1, p. 404.

20 Archivo General de Simancas, Consejo y Juntas de Hacienda, leg. 320, núm. 17: *Información hecha por la ciudad de Sevilla sobre los inconvenientes de que haya un solo bancow. También es Eufemio Lorenzo Sanz quien da la pista de esta información: 1980 , vol. 1, p. 158. 
para fortuna suya, gracias a su penetración para conocer y juzgar a las personas ${ }^{21}$.

Por lo que sabemos, Pedro Luis de Torregrosa se empleó por primera vez en asuntos al servicio de la Corona el año de 1554 , en que, dando cumplimiento a la cédula de 29 de enero, se ocupó de acuñar moneda de las partidas de oro y plata que se tomaron para atender a las necesidades reales ${ }^{22}$.

De acuerdo con las cédulas de 18 de diciembre de 1555 y de 11 de marzo de 1556, Torregrosa se encargó del beneficio y depósito de la plata obtenida en las minas de Guadalcanal. La relación que sus hijos presentaron a Felipe III dice que trabajó en tal labor hasta 1558, aunque nosotros hemos detectado un pequeño incidente en ese servicio, de acuerdo con la documentación aportada por Tomás González ${ }^{23}$.

De la época en que Pedro Luis de Torregrosa fue depositario de las minas de Guadalcanal se conserva un libro de cuentas, de pliego horadado, siguiendo el sistema de cargo y data, que da cumplida razón de su gestión y arroja luz sobre las vicisitudes de estos primeros tiempos en la explotación de las ricas minas recién descubiertas ${ }^{24}$.

Desde 1559 hasta 1562 parece que Torregrosa desempeñó el cargo de factor en la Casa de la Contratación de las Indias, en Sevilla ${ }^{25}$. Parece ya más dudoso que lo siguiera siendo en 1569, según afirma Lohmann Ville$\mathrm{na}^{26}$, pues para entonces tenía arrendado el almoxarifazgo mayor de Sevilla y era recaudador mayor del mismo 27 .

En cualquier caso, la cédula de 23 de noviembre de 1560 le ordenó que fuera a Toledo para intervenir en unas consultas que se estaban haciendo, en orden a determinar si era conveniente que la Corona asumiese por su cuenta, en régimen de monopolio, el comercio con las Indias de algunas mercaderías especialmente valiosas e interesantes, tal como lo hacían los reyes de Portugal con las especias ${ }^{28}$. Fruto de esta estancia en la Corte fueron dos memoriales que tratan del tema con bastante amplitud, profundidad y conocimiento de causa ${ }^{29}$. En ellos se tratan, además, de pasada, algunas otras

" Biblioteca Nacional, Mss. 1750 , fols. 364 r." a $365 \mathrm{v}$."

"Relacion de los Servicios del Contador Pedro Luys de Torregrosa, fol. 206 r.. 368 , etc.

T. González, 1831, tomo 1 , pp. $73,76,102,111,166,218,229,248,189,331$,

24 Archivo General de Simancas, Contaduría Mayor de Cuentas, 1. época, leg. 1102.

25 E. Schaefer, 1935 , tomo 1 , p. 381. Véase también carta de renuncia de un juro en favor de Nicolás de Grimaldo, de 24-I-1562, Archivo General de Simancas, Mercedes y Privilegios, leg. 193, expediente 35.

26 G. Lohmann Villena, 1968, p. 117

27 Archivo Histórico Nacional, Consejos, Pleitos, leg. 51085, expediente 2, fol. 66 r.".

2* Relacion de los servicios del Contador Pedro Luys de Torregrosa, fol. 206 r." y v.:.

29 Una versión de estos nemoriales se encuentra en el Archivo General de Simancas, 
cuestiones no relacionadas directamente con el problema del comercio real con las Indias, como, por ejemplo, la concerniente a las tareas de los oficiales de la Casa de la Contratación y la de la reglamentación del comercio del azogue, tema muy importante en aquellos momentos, pues el dicho metal se había mostrado necesario para la mejor explotación de las minas de plata de pobre contenido, merced al procedimiento puesto en práctica por el sevillano Bartolomé de Medina. Por otra parte, los razonamientos de Pedro Luis de Torregrosa, contrario a que la Corona tomara a su cargo el comercio con las Indias, persuadieron al Consejo a que abandonara sus proyectos en ese terreno, que en otro caso hubieran tenido consecuencias importantes.

Parece que, de 1562 a 1573, Torregrosa no estuvo ocupado al servicio del rey, sino que se dedicó a sus negocios particulares ${ }^{30}$. En 9 de marzo de 1563 otorgó testamento, en Málaga, Francisco de Mendoza, antiguo visitador general de las minas castellanas y, luego, capitán general de las galeras de España. Torregrosa había trabajado a sus órdenes durante su período de depositario de las minas de Guadalcanal, ocasión que le habría permitido, por lo visto, anudar una estrecha relación amistosa con él, por cuanto en el citado testamento, abierto el 31 de agosto del mismo año de su otorgamiento, se le designa testamentario, comisario y ejecutor de la última voluntad del difunto, junto con otras personas. Esta encomienda le ocasionó a Pedro Luis de Torregrosa sinsabores y engorrosos pleitos que amargaron su vida $y$, tras su muerte, la de sus herederos ${ }^{31}$.

Desde 1567 hasta 1572, Torregrosa tuvo arrendado el almoxarifazgo mayor de Sevilla, por el que pagó la cantidad de 150 millones de maravedís. Para este período de la vida y actividades de nuestro personaje, contamos con el «Libro de las quentas del almoxarifazgo mayor de Sevilla de los años de $1567,1568,1569,1570,1571,1572$ de que fue recaudador mayor $\mathrm{P}^{\circ}$ Luis Torregrosa, veinte y cuatro de Sevilla», que nos ofrece cumplida información sobre su gestión al frente de dicha aduana ${ }^{32}$.

Como consecuencia de su actuación a cargo del almoxarifazgo mayor, le surgió a Torregrosa otro de esos pleitos que, de una forma u otra, le acompañaron a lo largo de toda su vida. El día 6 de agosto de 1578 se personó en

Consejo y Juntas de Hacienda, leg. 2024. He hallado también otra versión en la Biblioteca del Real Monasterio de San Lorenzo de El Escorial, Mss. L-I-12, fols. 130 r.” a 137 r.․

* Relacion de los servicios del Contador Pedro Luys de Torregrosa, fol. 207 r.․

31 Véanse fols. 1 a 35 del tomo E-39, Colección Salazar, Biblioteca de la Real Academia de la Historia, así como la" declaración de Pedro Luis de Torregrosa ante el juez Urbán de Prado, del 11 de agosto de 1578, en Archivo General de Simancas, Expedientes de Hacienda, leg. 753, expediente núm. 45. También, el informe sobre un memorial de «los testamentarios de don Francisco de Mendozaw, Archivo General de Simancas, Consejo y Juntas de Hacienda, leg. 2017.

${ }_{32}$ Archivo General de Simancas, Contaduría Mayor de Cuentas, 1.2 época, legs. 1397 y 1403 . 
Sevilla un juez ejecutor residente en la Corte, Urbán de Prado, reclamándole un total de 6.406.753 maravedís, por diversos conceptos. Como Pedro Luis de Torregrosa se resistió a entregar lo que se le pedía, alegando no ser ciertas las reclamaciones que se le hacían, el juez ejecưtor le recluyó «en las casas del cavildo de esta dicha ciudad, adonde se acostumbra tener presos las personas de su calidad», según expresa el correspondiente auto de prisión, del 11 de agosto de dicho año de 1578. Se procedió también al embargo de sus bienes muebles e inmuebles, incluidos los juros y censos. Con esta ocasión, le salieron por fiadores un tal Vicente de Torregrosa y Miguel Pérez Collado, su sobrino y colaborador durante toda su vida. Gracias a la intervención del monarca, que le llamó a la Corte para evacuar una consulta, según cédula del 25 de septiembre de 1578, pudo salir Torregrosa de la cárcel, después de haber pasado más de un mes en ella ${ }^{33}$.

Durante estos mismos años de 1567 a 1572 tuvo también arrendados Pedro Luis de Torregrosa los derechos de saca de las lanas que salían por el almoxarifazgo mayor y sus distritos, así como por los puertos secos entre Castilla, Aragón y Valencia, además de las que se extraían por el obispado de Cartagena, reino de Murcia, marquesado de Villena, arzobispado de Sevilla y obispado de Málaga y Cádiz. Parece que pagó por este arrendamiento un precio anual de 23 millones de maravedís, mientras la recaudación se elevó durante el período a una media de 40 millones al año ${ }^{34}$.

Por una cédula del rey, de 23 de diciembre de 1572, parece que Pedro Luis de Torregrosa pasó a ocuparse de la administración, por cuenta de la Corona, del almoxarifazgo mayor de Sevilla para los años 1573 y $1574^{35}$.

No tenemos ninguna otra noticia que confirme este hecho, pero conocemos una carta que Torregrosa dirigió, en 6 de febrero de 1574, a Juan de Ovando, que a la sazón era presidente de los Consejos de Hacienda y de Indias, en la que le hace diversas reflexiones relativas al estado general de la Real Hacienda y a la forma de desempeñar los juros en poder de ciudadanos de Sevilla ${ }^{36}$. En ese mismo año parece que fue cuando se empezó a hablar de la conveniencia de llevar las cuentas de la Hacienda Pública castellana por el método de la partida doble o libro de Caja, y de encomendarle este menester a Torregrosa, aunque no se ha encontrado ninguna prueba de

${ }^{33}$ «Processo executivo contra Pedro Luis de Torregrossa, arrendador que fue del almox mayor de Sevilla», Archivo General de Simancas, Expedientes de Hacienda, legajo 753 , expediente 45 .

${ }^{34}$ Archivo General de Simancas, Contaduría Mayor de Cuentas, 3.. época, leg. 1704, núm. 42; íd., Consejo y Juntas de Hacienda, leg. 2017. También, Modesto Úlloa, 1977. pp. 330 y s.

${ }^{35}$ Relacion de los servicios del Contador Pedro Luys de Torregrosa, fol. 207 r.:.

36 Instituto de Valencia de don Juan, caja 37, envío 24. Cita también esta carta Mo desto Ulloa, 1977, p. 281. 
estas conversaciones, excepto la indicación que sobre ellas se hace en la Relacion de lo que passo, sobre la introducion del libro de caxa de la Real Hazienda ${ }^{37}$.

Sí sabemos de cierto, en cambio, que en un escrito remitido al rey en noviembre de 1573 se cita a Pedro Luis de Torregrosa como uno de los tratantes $\mathrm{y}$ hombres de negocios a los que podrían encomendarse funciones importantes en relación con la gestión y administración de la Hacienda del rey ${ }^{38}$.

Desde 1575 a 1581, Pedro Luis de Torregrosa sirvió en la administración de las alcabalas de Toledo, Ciudad Real, Ubeda, Baeza, Ecija, Carmona y Jerez de la Frontera, según se pone de manifiesto por multitud de pruebas documentales ${ }^{39}$. Parece que con carácter previo a todo esto, y en virtud de unas instrucciones de Juan de Ovando, contenidas en sus cartas de 29 de noviembre de 1574 y de 12 de enero de 1575, Torregrosa se había desplazado desde la Corte hasta Sevilla al objeto de hacerse cargo, en comisión especial, del encabezamiento de las alcabalas de esta ciudad ${ }^{*}$.

La gestión misma de Torregrosa en la administración y encabezamiento de las alcabalas de las ciudades antedichas durante los años en cuestión se conoce también bien, gracias a los documentos contenidos en el proceso de resultas que se le abrió o reabrió en 4 de marzo de 1595, después de haber sido requerido a rendir sus cuentas en varias ocasiones, según se dice ${ }^{41}$.

Como se ha apuntado más arriba, la cédula dada en Badajoz el 9 de julio de 1580 abre el intento de implantar la contabilidad por partida doble en las Cuentas Públicas de Castilla ${ }^{42}$. En efecto, por ella, el rey le encargaba a Pedro Luis de Torregrosa que, durante el término de un año, formara un libro de Caja encuadernado para llevar la razón y cuenta general y particular de la Real Hacienda. La decisión había sido tomada, sin embargo, antes de esa fecha, como consecuencia, según parece, de largas deliberaciones y consultas. Por una carta dirigida al rey en 15 de mayo de 1580 , sabemos que Felipe II había decidido tal implantación en Carnaval, manteniéndose, no obstante, el secreto sobre la medida, en espera del momento oportuno para

\footnotetext{
${ }^{37}$ Fol. 1 r.. vío 24.

3t Biblioteca Nacional, Mss. 12179; Instituto de Valencia de don Juan, caja 37, en-

${ }^{39}$ Relacion de los servicios del Contador Pedro Luys de Torregrosa, fol. 207 r. ${ }^{\circ}$ y v.; Relacion de lo que passo, fol. $1 \mathrm{r} .{ }^{\circ}$; Modesto Ulloa, 1977, p. 199. Las fuentes documentales a que se hace referencia se hallan en el Archivo General de Simancas, Patronato Real, legs. 74, 75, 76 y 77. También, en el Archivo Histórico Nacional, Consejos, Consultas de Gracias, leg. 4400, expediente 2.

* Archivo General de Simancas, Contaduría Mayor de Cuentas, 3." época, leg. 1704, núm. 42.

"I Ibidem.

'Se pueden encontrar dos ejemplares de esta cédula en el Archivo General de Simancas, Quitaciones de Corte, leg. 38.
} 
hacerla pública ${ }^{43}$. En cualquier caso, no parece que lo dispuesto en la cédula real indicada llegara a tener efectividad, como comenta el propio Felipe II en la cédula siguiente, de 2 de noviembre de 1592, confirmando el nombramiento y el encargo hecho a Torregrosa. Dice así el monarca: "Porque algunos ministros a quien por pliegos firmados de vuestro nombre pedistes os diesen quenta y razon, y los restos de lo que devian y estava a su cargo, y eran obligados conforme a la dicha mi cedula, vos pusieron algunas dificultades y otros impedimentos, y os dexaron de dar lo que ansi les pediades, no pudistes proseguir y llevar adelante el dicho libro de caxa.»

Lo cierto es que el proyecto de establecer la contabilidad por partida doble para llevar las cuentas de la Real Hacienda encontró, desde el principio, la enemiga de numerosos personajes y funcionarios de la Corte y de los círculos financieros de la misma; en unos casos, por la resistencia de los interesados en no ser sometidos a un control más eficaz y riguroso; en otros, por la irritación de los que veían en la medida una pérdida o menoscabo de su posición e influencia efectivas. La oposición no menguó en el segundo intento, sólo que la decidida voluntad del monarca, presente otra vez en la Corte y liberado de las preocupaciones de la campaña de Portugal, que habían retenido su atención en la primera ocasión, logró imponer el sistema, que, sin embargo, debido sin duda a las dificultades intrínsecas de la organización hacendística de la época, no parece que llegara nunca a satisfacer totalmente las ilusiones que había alimentado.

Según Francisco Gallardo, parece que en 29 de julio de 1581 se promulgó una cédula estableciendo de nuevo el libro de Caja ${ }^{4}$. Por diversas razones, sin embargo, el testimonio de Gallardo no resulta del todo fiable, aunque bien pudiera ser que nos hallásemos en presencia de una prórroga del plazo de un año que primitivamente cubría la encomienda hecha a Torregrosa, según hemos visto.

Los hijos de Pedro Luis de Torregrosa manifiestan en su relación que, pese a los obstáculos encontrados y al hecho de que no percibiese ninguna remuneración por su labor, su padre no cejó ni un momento en el empeño, manteniendo a su costa, para ello, a varios oficiales.

En cualquier caso, y pese a estos pretendidos trabajos en el establecimiento del libro de Caja, el rey le fue encomendando a Torregrosa otros cometidos durante estos años. Así, por cédula de 21 de marzo de 1582 le ordenó que, junto con otros tres contadores, tomase las cuentas del marqués

${ }^{43}$ Véanse varias cartas al respecto en Instituto de Valencia de don Juan, caja 37, envío 24.

${ }^{4}$ F. Gallardo Fernández, 1805, p. 34. 
de Auñón, Melchor de Herrera, de los años 1565 a 1574, en que había sido tesorero general ${ }^{45}$.

En 19 de abril de 1583 presentó al rey, conjuntamente con Fernán López del Campo, un memorial sobre lo que convendría proveer en materia de ferias, tema que por aquellos años atraía la máxima atención ${ }^{46}$.

El año de $1584^{\circ}$ se ocupó, también por encargo del monarca, en la averiguación de las cuentas de Antonio Alvarez y Manuel Caldera, que habían estado a cargo de la renta de la seda de Granada durante la rebelión de los moriscos ${ }^{47}$.

En agosto de 1585, Pedro Luis de Torregrosa se trasladó a Monzón, siguiendo al rey, y permaneció allí hasta marzo de 1586, a las órdenes directas de Rodrigo Vázquez de Arce, presidente de la Hacienda. Corriendo el año de 1587 recibió a examen los libros de Lorenzo Spínola, poniendo de manifiesto unas irregularidades en la contabilización de los intereses de un contrato firmado con el rey, que no se habían asentado en los libros oficiales, al objeto de eludir lo dispuesto por el decreto de suspensión de pagos de $1575^{48}$.

En ese mismo año de 1587 informó al rey en el asunto del almoxarifazgo de Sanlúcar, cuyos derechos pretendía el duque de Medina Sidonia. Torregrosa demostró el daño que causaba el contrabando a través del portillo de «la berraca», en una cuestión que ya le había preocupado en sus tiempos de arrendador del almoxarifazgo mayor de Sevilla ${ }^{49}$.

En 1590, Pedro Luis de Torregrosa dispensa la aprobación a la obra de Bartolomé Salvador de Solórzano, que constituye el primer tratado de contabilidad por partida doble compuesto por un español, y que lleva por título: Libro de caxa y Manual de cuentas de Mercaderes y otras personas, con la declaracion dellos. El libro fue publicado en Madrid ese mismo año por la imprenta de Pedro de Madrigal. Gracias a esta aprobación, que no es el párrafo rutinario al uso, sino una autorizada crítica y una razonada ponderación de la obra, el nombre de Torregrosa es conocido por los historiadores españoles de la contabilidad.

El 2 de noviembre de 1592 tiene lugar, como ya se ha indicado, el segundo y definitivo nombramiento de Pedro Luis de Torregrosa como contador del libro de Caja, esta vez con el firme propósito del monarca de que

${ }^{45}$ Relacion de los servicios del Contador Pedro Luys de Torregrosa, fol. $208 \mathrm{r} .^{\circ}$ y v.०; Modesto Ulloa, 1977, p. 808.

to Archivo General de Simancas, Diversos de Castilla, leg. 10, núm. 20.

4 Relacion de los servicios del Contador Pedro Luys de Torregrosa, fols. $208 \mathrm{v}^{\circ}$ y $209 \mathrm{r}^{\circ}$.

4 Ibidem, fols. 209 r." y ss.

49 Biblioteca Nacional, Mss. 9327, fols. 217 a 226. 
se llevase a cabo, efectivamente, la implantación del sistema contable de la partida doble para llevar las cuentas de su Real Hacienda ${ }^{30}$.

Parece que el nombramiento llegó revestido de cierta aureola de importancia y trascendencia. De esta manera, uno de los contadores ocupados en las finanzas reales y que conocía a Torregrosa, al recibir una copia de la cédula real con el título, le escribió en estos términos: «E holgado ynfinito de leello, por ver quan anplio es y quanta merced y fabor haze en el su magestad a vuesa merced, pues, conforme a el, se dexa entender que le haze superyntendente de todos sus minystros» ${ }^{51}$.

No se libra Pedro Luis de Torregrosa tampoco esta vez de la fuerte oposición y de la resistencia pasiva de muchos personajes de la Corte, y en particular de algunos funcionarios empleados en la Contaduría Mayor de $\mathrm{Ha}$ cienda en el menester de llevar las cuentas por el sistema empleado hasta entonces, del «pliego horadado", con las típicas relaciones de «cargo y datta». Al analizar y evaluar el resultado de esta pugna no hay que olvidar que, al recibir su título por segunda vez, Torregrosa tenía ya setenta años de edad.

Al margen de su trabajo como contador del libro de Caja, Pedro Luis de Torregrosa siguió recibiendo encomiendas especiales del rey. Así, en 1593 y 1594 le vemos, en compañía de otro contador, tomando las cuentas a Antonio de Herrera de lo que había entrado en su poder con motivo de las composiciones de las casas de aposento en la Corte.

En 1595 intervino en el asiento que se hizo con los Fugger, por diez años, en relación con las maestrazgos y con las minas de mercurio de $\mathrm{Al}$ madén ${ }^{52}$.

Poco después le vemos intervenir en una Junta de Hacienda, en la que se encontraban, además, hombres como Francisco de Salablanca, Pedro Ortiz del Río, Gaspar de Paz, etc., que dio su dictamen, sobre diversas necesidades del reino, en 26 de agosto de $1596^{53}$.

Durante los años de 1601 a 1603 , muerto ya Felipe II, lo encontramos tomando las cuentas a Pedro Mejía de Tovar, del Consejo de Hacienda. Dos años más tarde, en 1605 y 1606 , se las toma, asimismo, en compañía de

so Archivo General de Simancas, Quitaciones de Corte, leg. 38. Se encuentran, además, Hernández Esteve, Esteban $(1984 b)$ : «Las cuentas de Fernán López del Campo, primer ejemplares de esta cédula en las secciones de Contadurías Generales, leg. 318; Contaduría Mayor de Cuentas, 3." época, leg. 912; Consejo y Juntas de Hacienda, leg. 308, núm. 21, etcétera.

${ }^{31}$ Archivo General de Simancas, Contaduría Mayor de Cuentas, 3." época, leg. 2502, núm. 12. Carta de Fernando Márquez del 20 de diciembre de 1592, desde Sevilla.

${ }_{32}$ Relacion de los servicios del Contador Pedro Luys de Torregrosa, fol. 212 r. y v.:.

33 Biblioteca del Real Monasterio de San Lorenzo de El Escorial, Mss. L-I-12, folios $1 \mathrm{r} .^{\circ}$ a $22 \mathrm{r} .{ }^{\circ}$. 
otros dos contadores, a Diego de Vergara Gaviria, en relación con su gestión al frente de la receptoría del Consejo de Indias ${ }^{54}$.

Conocemos también otros pequeños servicios, de índole muy diversa, prestados por Pedro Luis de Torregrosa a la Corona durante esos años. Uno de los más significados fue el de dar la idea de resellar la moneda de vellón, en lugar de fundirla y volverla a acuñar, cuando en 1603 se quiso duplicar el valor nominal de la que circulaba ${ }^{55}$.

Cuatro años después fallecía, según dijimos, dejando tras sí una vida rica en los más diversos y variados trabajos, en los empeños más comprometidos e impopulares, movido - así hay que creerlo- por un afán de eficacia y perfección al servicio del rey y de su Corona. Es realmente patético observar cómo escribe carta tras carta a los más apartados oficiales y contadores del reino, en un esfuerzo imposible por lograr hacer luz en la inmensa e inabarcable maraña de inconexas relaciones que constituían la trama de la Hacienda Pública. El mismo estuvo en prisión, según hemos visto, entre otras cosas, porque habían desaparecido de la Escribanía Mayor de Rentas unas relaciones que él había enviado a su debido tiempo, en un claro ejemplo de lo peligroso que podía resultar, incluso para sus servidores, el desorden imperante en la Real Hacienda. No parece que sus esfuerzos le granjearan muchas simpatías ni, al fin, fueran demasiado fructuosos. Pero, sin duda, iluminaron su figura con un halo de prestigio dentro de los círculos de profesionales.

\section{III}

Al instituirse, en 1592, el libro de Caja de la Real Hacienda, ésta se hallaba estructurada en las dos Contadurías ya establecidas desde antiguo y reorganizadas por los Reyes Católicos: la Contaduría Mayor de Hacienda y la Contaduría Mayor de Cuentas, supervisadas y coordinadas por el Consejo de Hacienda, de cuya cręación ya hemos hablado.

La Contaduría Mayor de Hacienda se ocupaba de todo lo relativo a la administración, cobro y distribución o gasto de las rentas reales, llevando también la contabilización de las mismas, pues esta tarea de la contabilidad recaía fundamentalmente en esta Contaduría y no en la de Cuentas, como a veces se ha tendido a pensar.

Por su parte, la Contaduría Mayor de Cuentas entendía en tomar las cuentas a todos aquellos que, por un motivo u otro, hubiesen tenido algo que ver con la recaudación o distribución de alguna renta, o hubiesen reci-

54 Relacion de los servicios del Contador Pedro Luys de Torregrosa, fols. 212 v. y 213 r...

Ibidem, fol. 213 r. ${ }^{\circ}$ y $v 0^{\circ}$. 
bido una comisión de servicio, determinando sus contadores de resultas los alcances o saldos que, en su caso, deberían los interesados ingresar en la Hacienda. Para ello se servía esta Contaduría de las cuentas o datos proporcionados por la Contaduría Mayor de Hacienda, que compulsaba con las cuentas presentadas por los auditados y con los justificantes y comprobantes que aportaban.

El Consejo de Hacienda supervisaba la labor de las dos Contadurías, ejerciendo un cometido de doble dirección. Por un lado, asesoraba al rey y centralizaba la información y la contabilidad general o «al por mayor»; por el otro, transmitía las instrucciones del monarca y velaba por su cumplimiento.

La tarea de llevar la contabilidad de las Cuentas Públicas la realizaba la Contaduría Mayor de Hacienda a base de varios libros principales, que se llevaban en unas secciones llamadas contadurías de libros. Al establecerse la contabilidad por partida doble, por medio del libro de Caja, las contadurías que entonces ya existían eran las siguientes:

- Contaduría del Libro de Rentas, que comprendía también los libros de lo Salvado y de las Quitaciones.

- Contaduría del Libro de Relaciones.

- Contaduría del Libro del Sueldo, Tenencias y Acostamientos.

- Contaduría del Libro de las Mercedes.

- Contaduría del Libro de la Razón.

Además de los libros que daban nombre a las contadurías, y que eran llevados por duplicado, a fin de poderlos cotejar y puntear uno con otro en beneficio de la mayor seguridad de las anotaciones, cada contaduría llevaba también otros varios más, complementarios y auxiliares, para contabilizar de la forma más adecuada posible la parcela que les estaba encomendada. El sistema contable utilizado recibía la denominación de «libro común» o «libro de pliego horadadon, aunque, en realidad, y a pesar del nombre, no se utilizaba libro encuadernado alguno, sino unos pliegos sueltos, de cuatro páginas tamaño folio cada uno, perforados con un agujero de dos o más centímetros de diámetro, en la confluencia aproximada del eje horizontal delimitando el tercio superior del folio y el eje vertical señalando el tercio izquierdo del mismo. Por la perforación resultante se pasaba una cinta, que se ataba con la suficiente holgura para permitir volver y pasar fácilmente los pliegos, pero impidiendo que éstos se desordenasen. El conjunto resultante era lo que formaba el llamado «libro de pliego horadado», al cual se le iban añadiendo e intercalando hojas, es decir, pliegos, a medida que se precisaban, en una modalidad precursora de los actuales libros de hojas intercambiables. 
Aun cuando tal fórmula de ordenación no era, por supuesto, privativa de las anotaciones contables, sino que se utilizaba para todos los papeles necesitados de archivo y custodia, to cierto es que configuró un determinado método de contabilidad, denominado de «cargo y datta», que se basaba en relaciones de cargo a personas concretas, por el concepto de fondos o valores recibidos por cuenta del dueño de los libros, seguidas de otras relaciones de descargo o «datta», por los fondos o valores que estas mismas personas habían entregado por cuenta del indicado dueño; todo ello con los oportunos resúmenes y comparaciones entre los totales cargados y abonados, y la determinación del «alcance» o saldo.

Como ya se ha comentado más arriba, el segundo nombramiento de Pedro Luis de Torregrosa, llevado a efecto por cédula del 2 de noviembre de 1592, no se produce sin oposición. Según se comenta en la Relacion de lo que passo, sabre la introducion del libro de caxa de la Real Hazienda, algunos altos cargos de ésta, viendo la firme determinación del monarca de implantar la partida doble para llevar las Cuentas Públicas, le elevaron un memorial exponiéndole las razones por las cuales «no convenia que se introduxesse tal oficion. El rey remitió el memorial al licenciado Pablo Laguna para que éste se lo entregase a Torregrosa a efectos de contestar las objeciones. Estas se elevaban a veinticinco, a las que Torregrosa respondió cumplidamente.

Viendo los adversarios del libro de Caja que sus impugnaciones no habían bastado para mover al rey a que cambiase de opinión, presentaron un segundo memorial en el que abundaban en los mismos reparos presentados anteriormente. Torregrosa contestó a este segundo memorial en el mismo sentido en que había respondido al anterior ${ }^{56}$.

Una vez en poder de los dos memoriales, junto con las respectivas respuestas, Felipe II pasó de nuevo toda la documentación al licenciado Laguna, al objeto de que éste la sometiese a fray Nicolás Doria, vicario general de los Carmelitas Descalzos, y a Tomás Fiesco, genovés, que había sido nombrado poco antes factor general de todos los reinos, estados y señoríos de Su Majestad ${ }^{57}$.

El informe de Nicolás Doria, o Nicolás de Jesús María, según el nombre que había adoptado en religión, y de Tomás Fiesco fue totalmente favorable a la implantación del libro de Caja. A su recepción, el licenciado Laguna les volvió a preguntar, en nombre del rey, su parecer respecto de la instrumentación que debía darse a la nueva instancia contable. Este nuevo parecer, firmado conjuntamente con Pedro Luis de Torregrosa, lo entregaron en 20 de septiembre de 1592, afirmando que les parecía correcta la instrumentación prevista en la cédula de Badajoz, de 9 de julio de 1580. También considera-

${ }^{56}$ Relacion de lo que passo, fols. $1 \mathrm{r} .^{\circ}$ y ss.

"Archivo General de Simancas, Quitaciones de Corte, leg. 40. 
ban adecuada la remuneración global solicitada por Torregrosa, por la suma de 2.900 ducados al año, teniendo en cuenta que la plantilla prevista se elevaba, aparte del propio contador, a dos oficiales mayores, dos oficiales menores y cuatro escribientes ${ }^{58}$.

En 4 de octubre de 1592, el licenciado Laguna hace seguir a Felipe II este último parecer de Doria y Fiesco, manifestándole su conformidad a todo lo expuesto, a excepción del salario, que le parece excesivo, proponiendo por ello que se reduzca a 2.000 ducados anuales. Este mismo día, Felipe II contesta al licenciado Laguna, en una breve nota, signada de puño y letra con su inicial, dando su aprobación al proyecto y exponiendo el deseo de firmar personalmente el título de Pedro Luis de Torregrosa, con lo cual pone una vez más de relieve el afecto que le dispensaba y la importancia que confería al establecimiento de la contabilidad por partida doble para llevar las cuentas de su Real Hacienda ${ }^{59}$.

En la cédula de nombramiento se le encomienda a Torregrosa que lleve, por orden del libro de Caja y su Manual, «la quenta y razon general, y particular, de toda nuestra hazienda», pasándose luego a especificar que tal cometido significaba que había de llevar la cuenta de los siguientes capítulos ${ }^{60}$ :

- La cuenta de las alcabalas y tercias.

- La cuenta de los servicios.

- La cuenta de cualesquier otras rentas ordinarias y extraordinarias pertenecientes a la Corona de Castilla.

- La cuenta de todo lo que venía de las Indias para el rey.

- La cuenta de las penas o multas aplicadas en los reinos de Castilla en favor de la Corona o del fisco.

- La cuenta de los alcances de cuentas establecidos en la Contaduría Mayor de Cuentas.

- La cuenta de las rentas de los tres maestrazgos de las Ordenes militares de Santiago, Calatrava y Alcántara.

- La cuenta de las bulas de la Cruzada, de los Subsidios y del Excusado, así como de cualesquier otras gracias concedidas por el Papa.

- La cuenta de las ventas, arbitrios, asientos, cambios y todas las otras contrataciones, expedientes y cuestiones de cualquier clase tramitadas por el Consejo de Hacienda.

- La cuenta de todo lo asentado y contabilizado en los libros de la razón, a cargo, en esos momentos, de Alexo de Olmos y Juan Saravia.

- La cuenta de todo lo que se hubiera entregado y debiera entregarse

3s Archivo General de Simancas, Consejo y Juntas de Hacienda, leg. 292, núm. 21.

${ }^{59}$ Ibidem, leg. 292, núm. 31 .

to Archivo General de Sinıancas, Contaduría Mayor de Cuentas, 3." época, leg. 912. 
aún a mercaderes y hombres de negocios, en relación con el decreto de suspensión de pagos de 1 de septiembre de 1575, y con el medio general que se mandó tomar después al respecto, en 5 de diciem. bre de 1577.

- La cuenta de los acuerdos particulares tomados con los hombres de negocios de Flandes.

- La cuenta relativa a cualesquier otros negocios concertados con cualquier persona, tocantes a rentas o patrimonio del rey, tramitados por cualquier Consejo o Tribunal, o por cualquier oficial o ministro de la Corte o de fuera de ella, de la índole que fuesen.

- La cuenta de todos los cargos contra el tesorero general y contra cualesquier otros tesoreros, pagadores y receptores de las penas de Cámara, y contra cualesquier otras personas, por lo que se les consignase, y librase, o entrase en su poder, de las rentas y hacienda del rey, así como de las libranzas que se girasen contra ellas, para que pagasen a terceros los importes respectivos o para otros efectos, de forma que hubiese y se llevase cuenta general y particular con todos.

El objetivo de esta encomienda tan general y omnicomprensiva era, por supuesto, el de que Torregrosa, merced al libro de Caja, donde, como hemos visto, debía tenerse cuenta y razón de todo el patrimonio y la hacienda del rey, «sin que faltasse cosa alguna», pudiera dar al monarca o al Consejo de Hacienda, siempre que fuera requerido, la relación general y particular del estado en que todo ello estuviese.

Se especificaba en la cédula de nombramiento que el establecimiento del libro de Caja no excusaba ni relevaba «a los demas nuestros Contadores de las obligaciones que tienen, conforme a sus oficios". Al mismo tiempo, se ordenaba a todos los contadores, oficiales y ministros que, a requerimiento escrito del nuevo contador del libro de Caja, le facilitasen toda la información que les pidiese para montar su contabilidad.

Parece que Pedro Luis de Torregrosa se tomó muy en serio su cometido, poniendo inmediatamente manos a la obra, al objeto de organizar la contabilidad por partida doble.

De esta manera, antes de acabar noviembre comenzó ya a enviar los pliegos previstos en la cédula de nombramiento a diversos funcionarios y contadores, solicitando le relacionasen las cuentas que estaban a su cargo. Conocemos la mayor parte de las cartas enviadas, con el detalle de los datos pedidos ${ }^{61}$. No todos los receptores de las mismas contestaron con prontitud y detalle a los requerimientos de Torregrosa, de modo que, al parecer, éste tuvo serias dificultades y fricciones con tal motivo. Esta circunstancia obligó

\footnotetext{
"Ibidem.
} 
al licenciado Pablo Laguna a dictar un auto, con fecha 13 de marzo de 1593, recordando a todos los funcionarios con cargo de Hacienda la obligación que tenían de facilitar a Pedro Luis de Torregrosa «entera y breve satisfacion de todo lo que pidiere» ${ }^{62}$.

Por otra parte, el disgusto sentido por los demás contadores de libros con motivo del establecimiento del libro de Caja y de la preeminencia de que, desde el principio, se le quiso dotar, se exteriorizó también en las rencillas que surgieron con ocasión del orden que debía seguirse en la toma de razón y la correspondiente firma de los documentos. El Consejo de Hacienda dictó un auto al respecto en 26 de enero de 1593, disponiendo que Torregrosa firmara inmediatamente después de los contadores mayores de Cuentas y de la Cruzada, y antes que los de la razón y todos los demás ${ }^{63}$. Este auto, sin embargo, no zanjó definitivamente la cuestión, por lo que el 16 de octubre de 1596 tuvo que dictar otro auto el presidente del Consejo de Hacienda repitiendo lo dispuesto en el anterior ${ }^{64}$. La Ordenanza 27, de 1602, insistió una vez más en el mismo asunto ${ }^{65}$.

Pedro Luis de Torregrosa, por su parte, no parece que diera muchas facilidades para conciliar los ánimos, pues dilataba a menudo el despacho de los asuntos, al objeto de aclarar todas las dudas que se le presentaban, $\mathrm{o}$ incluso suspendía el trámite, por no hacerse las cosas conforme entendía que estaban ordenadas, mostrando en ocasiones un espíritu rígido y hasta quisquilloso ${ }^{6}$.

La nueva contaduría, después de algunas vacilaciones iniciales y de llegársela a llamar incluso «del libro general de la hacienda real», pasó al final a ser conocida generalmente bajo la denominación de «contaduría del libro de caxa de la real hacienda». Este era el nombre que se usaba también corrientemente en los documentos para indicar que debían ser pasados a la misma para su toma de razón, después de fracasado el intento que hizo Pedro Luis de Torregrosa para que se hiciera constar siempre su nombre y apellidos de forma expresa, en lugar de la denominación del libro que servía ${ }^{\circ}$.

A pesar de todas las trabas administrativas, dificultades y resistencias, la Contaduría del Libro de Caja empezó a funcionar y a cumplir su cometido de establecer la partida doble para llevar las cuentas de la Real Hacienda. Por lo que parece, sin embargo, este trabajo nunca se llegó a considerar completado ni pudo colmar las esperanzas que se habían depositado en él. En

"2 Archivo General de Simancas, Contadurías Generales, leg. 318.

"3 Archivo General de Simancas, Contaduría Mayor de Cuentas, 3." época, leg. 912; ibidem, Consejo y Juntas de Hacienda, leg. 311, núm. 20.

"Archivo General de Simancas, Contaduria del Sueldo, 2. ${ }^{a}$ serie, leg. 2.

os Ibidem.

* Archivo General de Simancas, Contaduría Mayor de Cuentas, 3.^ época, leg. 912.

" Ibidem. 
la propia nómina de las quitaciones para el año 1606 , confeccionada poco antes de que Pedro Luis de Torregrosa muriera, en la partida correspondiente a éste se sigue poniendo la misma anotación que figuraba cuando se le hizo el encargo: «Por el travajo y ocupacion que tiene en formar un libro de caxa donde esta la raçon y quenta del estado de mi Hazienda» ${ }^{6 *}$.

Con todo, hay que reconocer que el trabajo realizado fue formidable. Por una «Relacion de los libros de caxa y manuales, y otros libros que ay encuadernados en el oficio del contador Pedro Luis de Torregrosa», confeccionada probablemente a primeros de 1597 , sabemos que para esa fecha se habían ultimado ya en la Contaduría del Libro de Caja gran número de libros correspondientes a la contabilidad por partida doble propiamente dicha, que era llevada de forma regular, además de otros libros que servían de registros, auxiliares, copiadores, etc. ${ }^{69}$.

Conocemos, así, que en los cuatro primeros años de existencia de la contaduría se habían completado cuatro libros de Caja o Mayores, amén de diversos Manuales o Diarios, pues el sistema empleado era de Diarios múltiples, por sectores de actividad. Los Diarios que se habían confeccionado ya eran los siguientes:

- Cinco Manuales de despachos de los libros de la razón.

- Cinco Manuales de despachos de relaciones.

- Un Manual de las tres gracias.

- Dos Manuales para despachos de las tres Ordenes.

- Dos Manuales para despachos de la Contaduría Mayor de Cuentas.

- Un Manual de despachos tocantes a penas de Cámara.

- Tres Manuales de receptorías de alcabalas.

- Un Manual de receptorías de millones.

- Tres Manuales de despachos «que se ponen por memoria de diferentes cosas que no se asientan en el libro mayor, sino la resulta dello con brevedad».

- Un Manual «en que se pone por memoria los previlexios que dan, por renunciacion, de unos a otros», es decir, de transmisiones de juros.

- Dos Manuales de despachos de ventas de juros, «de entrada por salida».

- Dos Manuales de privilegios de juros, «que se dan por venta nueva».

- Un Manual de despachos de juros situados en la Casa de la Contratación de las Indias, en Sevilla.

4 Archivo General de Simancas, Contadurías Generales, leg. 887.

"4 Archivo General de Simancas, Contaduría Mayor de Cuentas, 3." época, leg. 912. 
Además de los anteriores, se encontraban también en la Contaduría del Libro de Caja de la Real Hacienda otros libros encuadernados con la condición de auxiliares y registros, como se decía anteriormente. Aparte de ello, existían también numerosos libros de pliego horadado que se habían recibido de otras contadurías o que se llevaban a efectos no contables, como conocemos por otro inventario titulado: «Relacion de los libros de pliego agujereado que ay en el oficio del contador Pedro Luis de Torregrosa de relaciones que dieron algunos contadores y otras personas, y lo que despues se a ydo acrecentando en ellos y haciendo otros de nuebo para claridad de algunas quentas y resultas hasta passar al libro de caxa, como se ha hecho, la raçon que se a tomado y toma en los manuales del» ${ }^{70}$.

Por un importante manuscrito, compuesto, según todos los indicios, por Francisco de Molina, tercer y último contador del libro de Caja de la Real Hacienda, conocemos a grandes rasgos la organización de la estructura contable montada por Torregrosa. Confirma, efectivamente, este documento, titulado «Libro de Caxa», que la contabilidad se apoyaba en un sistema de Diarios múltiples, cuyas partidas se asentaban posteriormente en un único libro Mayor, como ya empezaba a llamársele. Así, según se dice en el citado escrito: «Se enpezo a ordenar este libro el año de 1593, poniendo en el nuebe Manuales», en que parece había quedado reducido el número, mayor, de los consignados en el inventario que hemos visto ${ }^{71}$.

Los Manuales que se llevaban en tiempos de Francisco de Molina eran los siguientes: «Dos de la Razón, en que se toma la de los despachos tocantes a los maravedís que se destribuyeron por quenta de su Magestad, o se resciven para su servicio, como las mercedes, limosnas, asientos, ventas y otros desta calidad.» $Y_{a}$ hemos visto que este mismo Manual existía en 1597, aunque no sabemos si se llevaban dos distintos a la vez, en razón de sus operaciones, o uno solo, repetido. Lo mismo ocurre en el caso de los "otros dos de Relaziones, en que se assientan las partidas que tocan a las Rentas Reales, por devitos o creditos de los thessoreros, receptores o recaudadores de ellas, y de lo que deven o an de aver los que tienen Juros situados perpetuos o por vida en ellos». Sigue el manuscrito: «Otro de las receptorias de alcavalas, donde se haze deudor el Reyno de los 1.050 quentos que montan en cada un año, conforme a su encabezamiento general, y por todos los partidos del se cargan los valores de cada uno a los thessoreros de ellos que estan encabezados, y se da credito al Reyno que esta deudor enteramente de todos.» Este Manual también está incluido entre los inventariados. El siguiente Manual era «otro de las tres Grazias, Cruçada, subsi-

Ibidem.

7 Biblioteca Nacional, Mss. 1750, fols. 364 r." a 365 v." 
dio y excussado, donde se tiene la quenta del valor de ellas, y en que se distribuyen, teniendola también con los que sirven a su Magestad con galeras en todos los puertos, $y$ de los sueldos que se les pagan de los prozedidos destas grazias». También este Manual se contaba entre los incluidos en el inventario examinado, al igual que los tres siguientes: «Otro de las penas de Camara, donde se tiene la Raçon de lo que procede y se destribuye de ellas»; "Otro de la Contaduria de quentas, en que se tiene de los gastos de aquel tribunal y de todos los alcanzes que se hazen a particulares que an dado quenta de sus cargos en aquellos libros", y "Otro de juros, en que se assientan los desempeños y ventas que se hazen por los thessoreros generales, conforme a las condiciones que tienen los Juros de donde dependen, por lo qual no resulta cargo ni data a su Magestad, y asi se nombra de entrada por salidaw. Además de estos nueve Manuales, sigue diciendo el manuscrito de Molina, "tienen otros libros de todos los juros situados sobre las alcavalas y Rentas Reales, en que ay razon de las personas que los tienen, con distencion de los partidos y precios. Otros de asientos y sacas, donde se ponen copias de todos los que se toman con los hombres de negocios y las lizencias de sacas que se les dan. Otros de diferentes relaciones de copias y comissiones, en que se ponen las de las cedulas, decretos, comissiones y papeles que, en algun modo, tocan a la hazienda Real». Como hemos visto, todos estos libros y algunos más todavía se relacionaban en los inventarios de 1597.

Es también de gran interés la descripción que hace el autor de este manuscrito de la forma en que era llevado el libro de Caja, haciendo referencia a que todo lo relativo a la Real Hacienda y «se assienta por menor en los ocho Manuales, excepto el de entrada por salida, se recopila en un libro Mayor. En el se arman las quentas de todas las calidades referidas, empezando desde las alcavalas y Rentas Reales, y continuando a las demas, graduadas por sus partidos y generos, y a estas se siguen las de todos los particulares que en cualquier modo son deudores o acreedores de su Magestad. Y este libro [está] governado con un avecedario, que tiene tantos [folios] como letras el Abc, poniendo cada una con las siguientes hasta la ultima para los nombres $y$ apellativos, como por ejemplo las quentas de Francisco Gomez se ponen en la $\mathrm{f}$ con la $\mathrm{g}$, y las demas de este modo, de suerte que con gran facilidad se halla lo que se busca en el libro, el qual esta correspondido por los dias del año con todos los Manuales, y ellos con el, por los numeros de las paginas. Es bisto con suma brevedad el estado de qualquier quenta para satisfazer y ajustar los despachos, sin que passe alguno por esta zensura que no lleve la puntualidad y justificazion necessaria al servicio de su Magestad y utilidad de sus vasallos».

Aunque escrito con parquedad, el anterior pasaje explica con suficiente claridad la organización y funcionamiento de la contabilidad llevada en la 
Contaduría del Libro de Caja, de forma que aun en el caso de que no conociéramos por los antecedentes el tipo de sistema contable de que está hablando, no tendríamos demasiada dificultad para reconocer que estábamos en presencia de una aplicación de la partida doble, descrita según las prácticas y usos de la época.

Con todas las limitaciones que pudieran achacarse a la contabilidad por partida doble llevada por la Contaduría del Libro de Caja durante los años 1593 a 1621 , en que fue suprimida dicha contaduría, derivadas de la dificultad de su establecimiento y teneduría en unas condiciones adversas de resistencia pasiva y de falta de transparencia administrativa, lo cierto es que el hallazgo de los libros confeccionados durante la experiencia revestiría el carácter de acontecimiento historiográfico de primera magnitud, pues proporcionaría la posibilidad de una visión general de incalculable valor sobre la situación y marcha de la Hacienda Pública castellana de este período, que difícilmente puede sustituirse a través de trabajosas y parciales búsquedas, siempre incompletas, a partir del resto de los libros de cuentas custodiados en los archivos. Desgraciadamente, sin embargo, a pesar de todas las indagaciones y pesquisas efectuadas hasta el momento, no me ha sido posible dar con este conjunto de libros que, a juzgar por lo visto para los primeros cuatro años de existencia de la contaduría, no bajará, de conservarse, de un total de 500 ó 600 volúmenes.

Su existencia, no obstante, puede darse totalmente por probada, gracias a los inventarios que hemos indicado, así como al manuscrito de Francisco de Molina. Por otro lado, he podido localizar en el Archivo General de Simancas dos libros Manuales que, en cierto modo, tal vez puedan servir para estudiar de forma más profunda la organización del sistema de partida doble establecido por Pedro Luis de Torregrosa, pues aunque corresponden a los años 1627 a 1629 y se forman al específico objeto de contabilizar el donativo pedido por el monarca Felipe IV para financiar la compañia que quería crear con banqueros italianos con el fin de regular la circulación de la moneda de vellón, parece que estos libros están planteados como parte integrante de una contabilidad global de la Hacienda Pública, utilizando cuentas de un cuadro que da la impresión de ser mucho más general y completo. En este sentido, tal vez puedan ser los indicados libros un rebrote aislado del sistema utilizado por la Contaduría del Libro de Caja o un resto sobreviviente a su naufragio ${ }^{2}$.

Al morir Pedro Luis de Torregrosa, el 12 de octubre de 1607, se hizo cargo interinamente de su oficio Miguel Pérez Collado, su sobrino y oficial mayor, que, como ya apuntamos más arriba, le había acompañado y ayudado

72 Archivo General de Simancas, Contadurías Generales, leg. 3251, libros 117 y 118. 
en sus diversos trabajos a lo largo de los últimos treinta años de su vida ${ }^{73}$. No obtuvo Pérez Collado, sin embargo, la merced que solicitaba de ser nombrado oficialmente contador del libro de Caja. Desempeñó el oficio durante algunos meses, pero en 6 de septiembre de 1608 fue nominado para él Miguel de Ipeñarrieta, que a la sazón ocupaba el cargo de contador de resultas y de la mesa de libros en la Contaduría Mayor de Cuentas ${ }^{74}$. Esta vacante fue la que finalmente se adjudicó a Miguel Pérez Collado, que de esta forma abandonó la Contaduría del Libro de Caja, que había contribuido a crear bajo las órdenes de su tío, Pedro Luis.

En 31 de diciembre de 1614 se nombró a Miguel de Ipeñarrieta secretaric de la Real Hacienda de Su Majestad, en sustitución de Pedro de Contreras, que había sido promovido al oficio de secretario de Justicia, del Consejo de Cámara. En esa misma fecha se despachó la cédula designando a Francisco de Molina para cubrir la vacante dejada por Ipeñarrieta como contador del libro de Caja ${ }^{75}$. Molina desempeñó el cargo hasta el día 12 de noviembre de 1621 , en que Felipe IV, que había subido al trono a la muerte de su padre, Felipe III, ocurrida en 31 de marzo de 1621, dictó una cédula disponiendo «que se consumiesen algunos oficios, agregando los exercicios dellos a otros, gozando de sus salarios las personas que los tenian, y que uno de los oficios que se han consumido ha sido el del libro de Caxa de. mi Real Hazienda, cuyo contador hera Francisco de Molina» ${ }^{76}$.

Esta decisión fue tomada por recomendación de una Junta que se había formado para la reforma del Consejo y de la Contaduría Mayor de Hacienda, siguiendo instrucciones del recién nombrado monarca $"$.

Con ella se pone punto final a esta interesante experiencia, que se prolongó durante cerca de treinta años, de llevar las Cuentas Públicas castellanas de forma centralizada y globalizada, merced a las técnicas de la contabilidad por partida doble, sobradamente conocidas y practicadas por los hombres de negocios y banqueros de la época. Al examinar la experiencia a lo largo de toda su singladura se gana la impresión de que, en sus últimos años, había perdido fuerza y se había degradado mucho en relación con el empuje que había sabido imprimirle Torregrosa en sus comienzos. Por eso, su supresión no parece que causara ninguna conmoción; pasó sin pena ni gloria, en agudo contraste con la polvareda levantada por su establecimiento.

\footnotetext{
${ }^{73}$ Archivo General de Simancas, Quitaciones de Corte, leg. 38.

74 Ibidem.

${ }^{75}$ Archivo General de Simancas, Quitaciones de Corte, leg. 18.

76 Ibidem.

$"$ Biblioteca Nacional, Mss. 6754, fols. 91 r." a 92 r.".
} 


\section{BIBLIOGRAFIA}

Cunrtas Rivero, Margarita (1981): «Los Tesoreros Generales de la Corona de Castilla en el siglo xvi (Orígenes de la Dirección General del Tesoro)m, en Presupuesto y Gasto Público, núm. 9.

Gallardo Fernández, Francisco (1805): Origen, progresos y estado de las rentas de la Corona en España, su gobierno y administración, Madrid.

Gonzńlez, Tomás (1831): Noticia histórica documentada de las célebres minas de Guadalcanal, desde su descubrimiento en el año de 1555, hasta que dejaron de labrarse por cuenta de la Real Hacienda, Madrid.

Hernández Esteve, Esteban (1981): "Legislation Castillane du Bas Moyen Age et du début de la Renaissance relative à la comptabilité et aux livres de comptes des marchandsm, comunicación presentada en las Journées Internationales d'Histoire du Droit, Valladolid, 1 a 3 de junio de 1981 . La versión española de esta ponencia será publicada en la revista Presupuesto y Gasto Público.

HeRníndez Esteve, Esteban (1983a): «Introducción al estudio de la influencia de la organización financiera de los Países Bajos en la creación del Consejo de Hacienda de Castilla (1523)», en Historia económica y pensamiento social. Estudios en bomenaje a Diego Mateo del Peral, editados por Gonzalo Anes, Luís Angel Rojo y Pedro Tedde, Madrid, Alianza Editorial.

Hernández Esteve, Esteban (1983 b): Creación del Consejo de Hacienda de Castilla (1523-1525), Madrid, Servicio de Estudios del Banco de España.

Hernández Esteve, Esteban $(1983 c)$ : "Tras las huellas de Bartolomé Salvador de Solórzano, autor del primer tratado español de contabilidad por partida doble (Madrid, 1590)», en Revista de Derecho Mercantil, núms. 167-168, Madrid.

Hernóndez Esteve, Esteban (1984a): «Estructura y funciones del Consejo de Hacienda de Castilla durante su proceso constituyente (1523-1525)m, en Cuadernos de Investigación Histórica, núm. 8, Madrid.

Herńndez Esteve, Esteban (1984 b): «Las cuentas de Fernán López del Campo, primer Factor General de Felipe II para los reinos de España (1556-1560). Contribución al estudio de la historia de la contabilidad y de la Hacienda Pública en España en el siglo XVIm, en Hacienda Pública Española, núm. 85.

Lо н мaNn VIllen, Guillermo (1968): Les Espinosa, une famille d'bommes d'affaires en Espagne et aux Indes à l'epoque de la colonisation, París.

Lorenzo SAnz, Eufemio (1980): Comercio de España con América en la época de Felipe II, Valladolid, 2 vols.

Madariaga, Pedro (1777): Arte de escribir, ortografía de la pluma y bonra de los profesores de este magisterio. Obra dividida en XII diálogos eruditos, Madrid (1." ed., 1565).

Pérez Bustamante, Rogelio (1979): «Un intento de reforma contable en la Hacienda española durante el reinado de Felipe II: el Libro de Cajan, en Moneda y Crédito, núm. 148, mayo.

Relacion de lo que passo, sobre la introducion del libro de caxa de la Real Hazienda (impreso, sin lugar ni año), Biblioteca de la Real Academia de la Historia, Colección Salazar, tomo T.53.

Relacion de los servicios del Contador Pedro Luys de Torregrosa, nuestro padre, que aya gloria, bizo a su Magestad en utilidad de su Real patrimonio (impreso, sin lugar ni año), Biblioteca de la Real Academia de la Historia, Colección Salazar, tomo N-49.

Salvador de Solórzano, Bartolomé (1590): Libro de caxa y Manual de cuentas de Mercaderes y otras personas, con la declaracion dellos, Madrid.

SCh AEFER, Ernesto (1935): El Consejo Real y Supremo de las Indias. Su bistoria, orga. nización y labor administrativa hasta la terminación de la Casa de Austria, Sevilla, 2 vols.

ULlon, Modesto (1977): La Hacienda Real de Castilla en el reinado de Felipe II, Madrid. 